\title{
Research on Models and Modernization of Logistic System in E-commerce
}

\author{
Hao Wang ${ }^{1}$, Huiyan $\mathrm{Li}^{2}$ \\ ${ }^{1}$ School of Tourism \& Hotel Management, Sanya Aviation \& Tourism College, P.R.China, 572000 \\ ${ }^{2}$ School of Management, Sanya University, P.R.China, 572022 \\ wh771201@126.com, linda770206@sina.com
}

\begin{abstract}
E-commerce brings about great changes to human society. It challenges to the conventional business and traditional enterprise management model as well. In electronic business, logistics is an important component during the transaction process that existed in industry age. However, sharp contradiction comes into being between flourishing E-commerce and backward logistics management. How establish the modern logistics system? How strengthen the management to logistics, so as to connect Internet transaction process successfully for getting used to the need of e-business, which become the faces problem in the development of E-commerce enterprises or organizations. It is essential for logistics to carry on innovation of management. This paper aimed at the model and modernization strategy of logistic system, discussed the close relations between E-commerce and logistics first, then, it also analyzes several available logistic models and the way that the enterprises use to choose its appropriate model. Ultimately, in this paper, some basic means in order to modernize E-commerce logistics are proposed, such as (1)plan and layout as a whole; (4) promote logistics informational construction; (2)optimize logistics system and network; (3)regard training of the logistics talents.
\end{abstract}

Index Terms - E-commerce, Logistics, Modernization, Third-party logistics

\section{Introduction}

In the new century, Internet breaks out the energy and it influence on each aspect of the society at the inflation speed of the geometric progression, the global economy will develop greatly in a bran-new model, and the management principles focus on E-commerce bring unprecedented huge variety in the economic structure, business model of the whole society. E-commerce develops quickly in China, 1999-2001 years is the stage from start into development, and the E-commerce market has stepped into the period of fast growth since 2002 .

In this process, the demand of the logistics is more and higher, pushing logistics transform from the tradition toward modern, so we have to change the tradition and laggard logistics idea, and to face the new challenge of the logistics under the E-commerce environment [1]. Actually, in this flourishing information society, the E-commerce and logistics have already combined together closely, they are inseparable, interdependence, mutual promotion and play a more and more important role in the modern society.

\section{The Interaction of E-commerce \& Logistics}

A. The new characteristics of the logistics in E-commerce

The emergence of the E-commerce brings global logistics a new development, making the modern logistics possess a series of new characteristics:

1) Information-based: At E-commerce ages, the information-based logistics is the necessary request of E-commerce. It mainly represent commercialization of the logistics information, the database and code in the information collection, the computerization in the information handle, the standardization and real timing in the information delivery and the numeration in the information storage, etc.. Therefore, the technique BC, DB, EOS, EDI, ERP, etc. will be applied extensively in logistics [2]. The information-based is the whole foundations, without it, any advanced technique can't apply in the logistics area. The information and computer technique will bring deep variety in the application in the logistics, catalyzing a new type of modern logistics.

2) Automatization: The foundation of the automation is information-based, the core of it is machine-electricity integrity, the manifestation of it is self-service, and the result of it is labor-saving. Moreover, automatization can extend the logistics working ability, increase labor productivity, reduce the logistics working mistake etc.

3) Networking: The logistics networking is the necessity of the logistics information-based, is one of the main characteristics in E-commerce logistics activities. The networking here has two meanings: one is the calculator communication network of the logistics distribution, such as the process that the logistics distribution center send orders to supplier, can use the calculator communication method, and implement automatically recur to EOS and EDI in VAN [3]. In the same way, the order process that the logistics distribution center sends to downstream customers can also complete automatically. The other is networking of organization, namely so-called organization intranet.

4) Intelligence: This is a kind of advanced application of logistics automation and information-based. But in the progress of the logistics automatization, intelligence is an inescapable technical problem. With the development of the world science and technology and the calculator network, the expert system, robotics and other related technique have already become more mature to solve above problems. In fine, in order to raise the logistics modernization level, the logistics intelligence has become a new trend in the E-commerce logistics development [4].

\section{$B$. The relationship between E-commerce and logistics}

Any transaction in e-commerce includes the four flows: information, fund, trade and logistics. Among them, the 
information flow includes the merchandise information offer, distribution and promotion, technique support, after-sales service and so on. The trade flow means a series of products transaction activities. The funds flow is the capital transfers process. Logistics, as the most special kind among the four, means the fluxion process of the product entity, such as conveyance, storage, packing and unloading, protection, distribution and the logistics information management and so on [5]. The relationship between the E-commerce and logistics is shown in the following Fig.1.

With the help of digital and communicational technology, E-commerce can integrate the previous three flows, but can't solve the logistics problem. Logistics is not only an necessary component of E-commerce, it also is powerful guarantee for E-commerce realization. In the whole transactional process of E-commerce, logistics appears as the latter and servicer of trade flow. Without the modern logistics, any easiest activities in trade flow will degenerate into a mere scrap of paper.

\section{The Logistics Model and Selection in E-Commerce}

\section{A. The basic model of E-commerce logistics}

For the company which setting foot in the e-commerce, the primary problem is making the decision of logistics mode. Under different environment, the company must choose the different logistics mode.

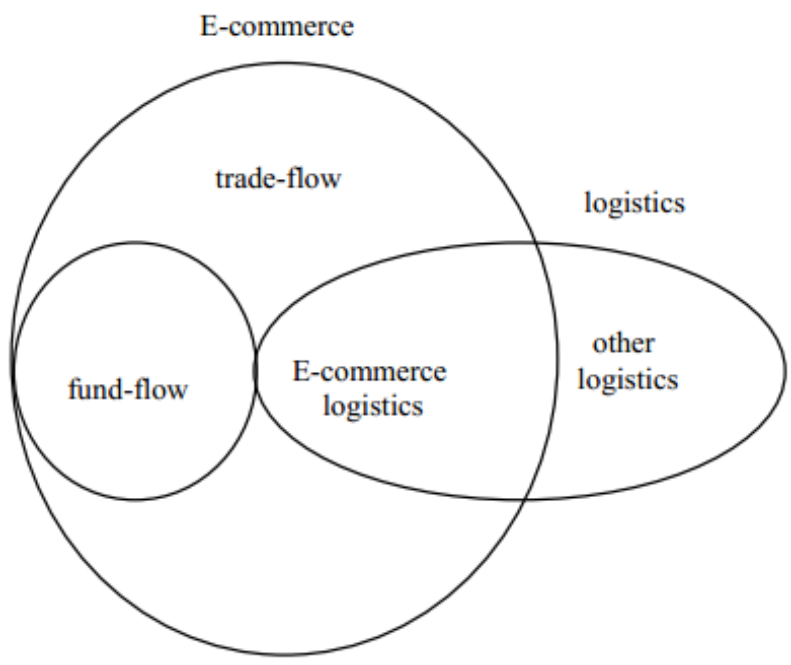

Fig. 1 The relationship between E-commerce and logistics

\section{1) Logistics integration agency}

Logistics integration agency means the operational activity that a logistics agent with preponderant integration management experience, person, technique and ideas surrogates all E-commerce logistics activities of both supplying and demanding with full powers [6]. As an important tache in supply chain system, the logistics agent prepares and manages the customer, transport enterprise, distribution center and warehouse business according to the logistics integral principle, such as the Fig. 2 show.

2) Third-party logistics

In order to adapt the development of the E-commerce, we can adopt the third-party to provide the logistics service. That is, the special logistic intermediary provides all or some business service for other companies in the certain period by signing contract. In broad sense, it includes the whole logistics activities, and the consignor can get value increment service from the professional logistics agent. Providing this service is base on the formal contract between the consignor and the agent. This contract ruled service charge, term and mutually responsibility etc. definitely [7]. But in the narrow sense, it means a kind of logistics management method that the agent responsible for replacing the consignor to complete the whole logistics process without fixed assets, in virtue of outside strength.

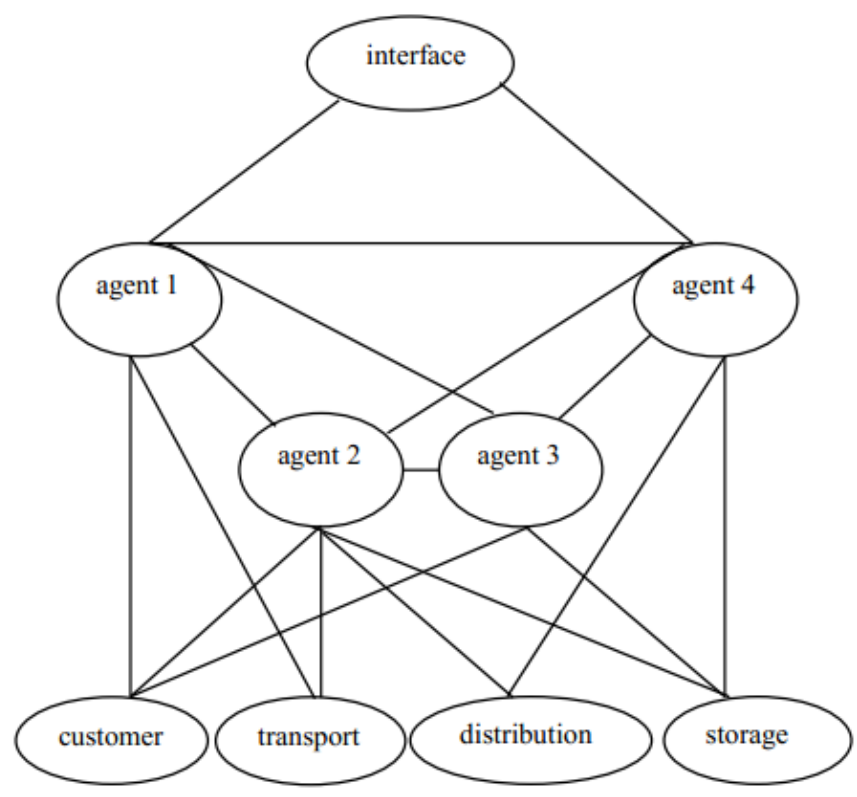

Fig. 2 Logistics integration agency

\section{3) Self-support logistics}

Self-support logistics is the model that the enterprise finished all the logistics activities itself such as the supply logistics of manufacturer's original material, components, assistance material and the distribution logistics of finished goods [8]. Along with the development of the modern logistics, self-support logistics need to integrate various function such as transport, packaging, loading, transit, consignment, storage, circulating, distribution, callback and information processing. Only so modern self-support logistics mode will match the principle "customer is \#1" in modern economy and supply service for the customer efficiently.

\section{4) Logistics enterprise alliance}

Logistics enterprise alliance means a kind of fellowship which is mutual predominance, double or omnidirectional flowing factor, trust mutually, common risk and income by signing the contract. The request of the professional logistics enterprise is the scale economy of logistics, for pursuing this kind of scale economy, the logistics alliance appears [9].

\section{B. The selection of logistic model}

The selection of logistic model in E-commerce mainly 
based on two factors - - logistic management ability of the enterprise and the logistic influence degree to the enterprise success.

If logistics is very important to the business enterprise success, and logistics processing ability of the business enterprise is very strong, namely the enterprise ( I ), can adopt the self-support model generally; If logistics has the key effect in the enterprise strategy, but the level of its processing logistics is lower, to this kind ( II ), it can obtain great benefit in logistics facilities, conveyance management and the profession management technique by building logistic enterprise alliance. And the enterprises (IV) which logistics is not very important in its strategy but with high level logistic management can select logistics integration agency, acquire the scale performance and lower logistics cost by enlarging amount of logistics; To those enterprises (III) which logistics position isn't very important and the processing ability is not very strong, it is the best choice to adopt the third party logistics. The decision-making model is shown in Fig. 3.

\section{Logistics Modernization Strategies in E-Commerce}

The uppermost characteristic of modern logistics is it manages each tache in the whole logistics process with modern technique and science, forms a integrated system in phase, makes the resource collocation the most excellent with the minimum investment and gets the best integer benefits. To realize the logistics modernization in E-commerce in China, we should take the following steps actively.

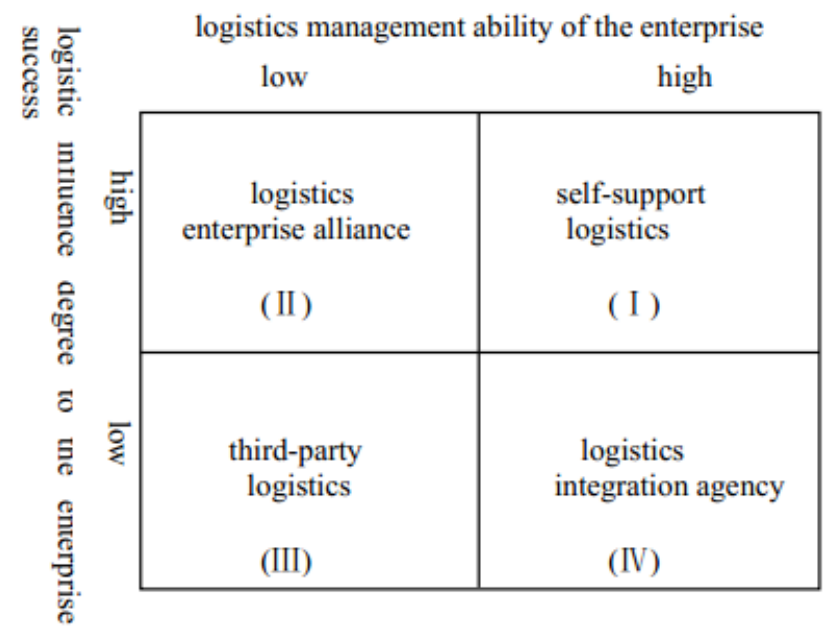

Fig. 3 The selection of logistic model

\section{A. Plan and layout as a whole}

It is necessary to put up unite layout and overall arrangement for building modern logistics system. First of all, we should constitute an authoritative nation logistics guidance or harmony institution. This institution mainly responsible for marking out nation magnitude logistics establishment item and joining the development programming, moreover, researching and establishing policies or codes in modern logistics evolution. Secondly, the industry department in each system should take charge of marking out logistics establishment item and establishing logistics technique standards, bylaw, long-term development scheme inside its system [10]. Furthermore, it is important to exert the serving, supervisal, corresponding and self-discipline functions of logistics guild, constructing equal competition and normative environment.

\section{B. Optimize logistics system and network}

The target of E-commerce logistics distribution is not simply deliver goods or storage, it needs not only motorcade and storehouse, but the most important thing is to design logistics system. Therefore, the operators must guide the design with modern logistics distribution theory, must make the logistics distribution system satisfy the E-commerce management objective with minimum cost, this is not mean that the least of the deliver goods or stock cost, but the least of the total logistics cost. This aim will achieved only when our ideas overstep the detail working under the modern logistics guidance.

\section{Regard training of the logistics talents}

Logistics network is the crystal of the logistics and Internet, belong to techno-compression industry. So, the growth of it exacts the professional talents with Internet and logistics business knowledge [11]. It is particularly important to establish effective training and promoting mechanism for logistics high-tech talents.

\section{Promote logistics informational construction}

Information management is the requirement of modern logistics development. The information network technique is the important part to form modern logistics system and the important technique guarantee to increase logistics service efficiency [12]. Logistics enterprises should draw logistics informational programming and make modern logistic information develop systematically, according to the trend of information network technique, relying on nation E-commerce environment, using foreign logistics information layout for reference.

\section{Conclusion}

At the turn of the century, people focus attention upon E-commerce because of its characteristic, infinitely global business chance and huge continuous development space. Simultaneously, as the third profit headspring, logistics grew rapidly. E-commerce can't develop without logistics, but it offers logistics scarce chance to expand and points out the evolution direction.

In recent years, although logistics in China has already possessed quite scale, its operational ability can't adapt the demand of economy development in E-commerce yet. Logistics benefit is not very high comparing with international. It is necessary to enhance logistics service system and constitute market competition mechanism and management code. To build modernization logistics, breaking E-commerce logistics bottleneck and promoting E-commerce development has already become the trend of times. 


\section{References}

[1] James C. Johnson, Contemporary logistics. Prentice Hall upper saddle river, pp.58-73, 2001.

[2] Lalonde. B. Mason, Some thoughts on logistics policy and strategies, International journal of physical distribution and logistics Management, vol. 24, 2004.

[3] Mac Exon-Taylor., Enterprise management----the logical integration of supply chain. Logistics information management, vol.3, pp128-164, 2001.

[4] Weiss. M. A., Implication of electronic exchange system for logistics planning and strategy. Journal of business logistics, vol.6, pp.68-72, 2002.

[5] Richer Trombly, "2002 Economic Outlook", Journal of industrial distribution, 2002.

[6] Sheffi Y., Third Party Logistics: present and future prospects. Journal of business logistics, vol.11, pp. 27-39, 2001.
[7] Michigan State University, 21st Century logistics: making supply chain integration a reality, pp. 25-68, 2002.

[8] Daugpherty P. J., Stank T. P., Third-party logistics service providers: purchaser's perception. International purchasing \& Material management, vol. spring, pp. 23-29. 2002

[9] Hughes. Mark Ralf and Bill Michele, Transform your supply chain----releasing value in business, International Thomson business press, pp. 95-98, September, 2002.

[10] Denis R. Towill. Industrial dynamics modeling of supply chain logistics information management, September, 2002.

[11] Hamalainen R. P., Seppalainen, The analytic network process in energy policy making, Soci-economics planning science, vol.8, pp. 45-54, 2002(8).

[12] Mouhamad Y. Rabah, Hani S. Mahmassani, Impact of E-commerce on logistics operations: a focus on vendor managed inventory strategies, Southwest region university transportation center, pp. 98-126, 2002. 